\title{
A medical history
}

Whether your interest lies in anatomy, pathology, surgery or the history of science, or, like myself, you are just curious, the reopening last month of the Hunterian Museum at the Royal College of Surgeons of England in London is an event to be celebrated.

Although only 3,500 of the Hunterian's collection of some 65,000 items survived the bombing of the museum in 1941 (right), the remainder of this great eighteenth-century 'cabinet of curios' still ranges over an extraordinary and wonderful breadth of natural science. From the treatment of gunshot wounds and syphilis, through the anatomy of the extinct giant deer, to tooth transplants, the life cycle of bees and a dissection of a coachman's leg (below right), there is something for everyone in this amazing collection, which has undergone a £3.2-million (US\$6-million) refurbishment.

The museum's founder, John Hunter (1728-93), was one of three brothers from Scotland who sought fame and fortune as surgeons in London. William, the eldest, was already well established when John joined him as an apprentice in 1748. After a career as an army surgeon, John married the talented Anne Home, who established a fashionable salon that attracted the great and the good of the day, from James Boswell to Joseph Banks. John was a workaholic who became successful as a surgeon, pathologist, teacher and experimentalist, and helped to lay the foundations of modern medicine. This is suitably celebrated by the excellent new displays put together by curator Simon Chaplin and his team. William Hunter's collection is at the Hunterian Museum in Glasgow.

www.rcseng.ac.uk/services/museums
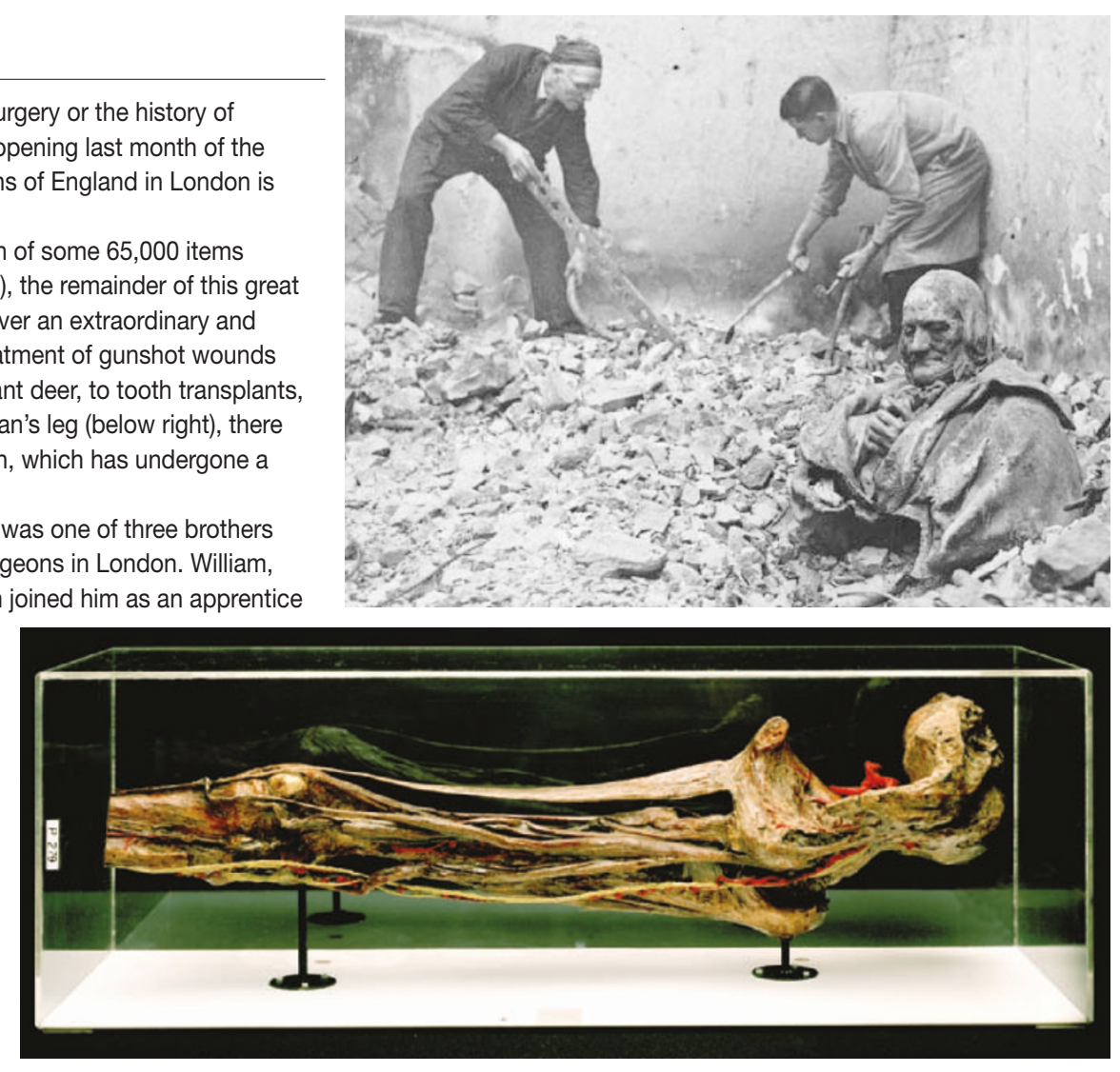

a tendency to limit their contributions in research collaborations to advising or determining how measurements should be analysed, and how many should be taken, rather than what the measurements should be. Even in the field of experiment design, the emphasis is on choosing patterns of inputs to the experiment, rather than advising on the measurement of outputs.

My field is medical statistics and although I take some measurement issues seriously, I shy away from others. I always find, for example, that whenever I have anything to do with quality of life, mine suffers and I avoid thinking about it accordingly. An honourable exception among statisticians is David Hand, who originally trained as a mathematical physicist. Since his conversion to being a statistician he has worked in psychology and medicine, as well as on economic and financial topics such as credit scoring. Hand, who is professor of statistics at Imperial College London, has been worrying about issues concerning measurement for years and has now written this thought-provoking monograph.

There are two different sorts of chapter in the book. The first four cover matters of fundamental importance for all sciences: a general introduction is followed by discussions of the nature and process of measurement and accuracy. The last five chapters cover various sciences - psychology, medicine, the physical sciences, economics and the social sciences - and include a final remain- der chapter to sweep up all terms not covered by the preceding expansion. My one major criticism is that there isn't a chapter on statistics itself: there are just three pages on probability in the final chapter. More could have been said about this. For example, is measure theory fundamental or a fundamental mistake as maintained by Glen Shafer and Vladimir Vovk in their book Probability and Finance (Wiley, 2001)? Other omissions include any discussion of the measurement of political preferences and, for example, Condorcet's paradox and Arrows' impossibility theorem and their implications for the impossibility of perfect voting systems.

However, the book is full of wonderful things. Here is Hand writing about Luce's principle governing the classes of possible relationships between variables, which has implications as to the sort of scientific laws that are possible: "To me, when I first heard of the idea and saw its implications, it seemed remarkable, lending extraordinary power to the search for scientific laws." I have also now had such a revelation, but its source was Hand's book and the valuable discussion of Luce that it contains, both in chapter 2 (whence the quote) and later in chapter 7 on the physical sciences. This latter chapter also has excellent discussions on dimensional analysis and the implications for regression coefficients.

Hand also sheds light on the baffling and notorious 'two-envelopes puzzle' (also known as the 'exchange paradox'). You are given a choice of two envelopes and reliably informed that one contains twice as much money as the other. Having picked one, but not yet opened it, you argue: "If I exchange, I double my money with a probability of one-half, and halve it with probability of one-half, and since half of two plus half of a half is one-and-a-quarter, my expectation is greater if I exchange." Having exchanged, you can then use the same argument to change back again.

Many other matters are expertly touched on too. To pick some, not at all at random, I found the discussions of the various forms of indirect scaling, of psychophysics, of indices in economics, and on league tables particularly interesting, and will find much of what is in the chapters on medicine and psychology useful in my work. The book is also pleasantly sprinkled with historical observations, interesting quotations and anecdotes. For instance, we learn of Claude Litre, born in Margaux in the heart of the Medoc (whose name speaks volumes, but of fiction in this case).

This book ought to be on every statistician's shelves and on those of many other scientists as well. The author concludes that "measurement is what distinguishes the civilized from the uncivilized". He is to be congratulated for this stimulating contribution to civilizing his fellow scientists.

Stephen Senn is in the Department of Statistics, University of Glasgow, Glasgow G12 8QQ, UK. 